\title{
Evaluation of Saliva as an Alternative Matrix for Monitoring Plasma Zidovudine, Lamivudine and Nevirapine Concentrations in Rwanda ${ }^{\S}$
}

\author{
Alain Gras ${ }^{*}$, , Serge Schneider ${ }^{2}$, Jean-Claude Karasi ${ }^{1}$, Anne-Marie Ternes ${ }^{1}$, Nicolas Sauvageot ${ }^{3}$, \\ Christine Karasi-Omes ${ }^{4}$, Anne-Pascale Henry ${ }^{5}$, Jean-Claude Schmit ${ }^{1,6}$, Carole Seguin-Devaux ${ }^{1}$ \\ and Vic Arendt ${ }^{1,6}$
}

${ }^{I}$ CRP-Santé, Laboratory of Retrovirology, Luxembourg; ${ }^{2}$ Laboratoire National de Santé (LNS), Division of Toxicology, Luxembourg; ${ }^{3}$ CRP-Santé, Centre d'Etudes en Santé, Luxembourg; ${ }^{4}$ Lux-Development, Luxembourg; ${ }^{5}$ Centre Hospitalier Universitaire de Kigali, Rwanda; ${ }^{6}$ Centre Hospitalier Luxembourg, Service National des Maladies Infectieuses, Luxembourg

\begin{abstract}
Saliva may provide interesting advantages as matrix for compliance measurements, pharmacokinetic studies and therapeutic drug monitoring in resource limited countries. We investigated the feasibility of using saliva for compliance monitoring of zidovudine (ZDV), lamivudine (3TC) and nevirapine (NVP) in $29 \mathrm{HIV}-1$ infected patients from Rwanda. ZDV, 3TC and NVP drug levels were quantified by an LC/MS-MS method in plasma and stimulated saliva samples and compared using Bland-Altman analysis. Seven patients demonstrated undetectable saliva ZDV levels while five out of these seven also showed no 3TC salivary concentrations. For the other samples, we observed a good agreement between salivary and plasma concentrations of each antiretroviral drug. A significant relation between the difference in saliva and plasma ZDV concentrations and the average ZDV concentration in the two matrices was deduced as follows: $y$ $=-380.15+1.79 \mathrm{x}$. The log saliva and plasma concentration difference of both 3TC and NVP was consistent across the range of average log concentration. Overall, we showed large agreement limits suggesting a wide inter patient variability that may result in non-reliable plasma level predictions from saliva drug measurements. Therefore, our results indicate that saliva may serve as a valuable tool only for NVP compliance testing because of its high salivary concentration.
\end{abstract}

Keywords: Developing countries, HAART, lamivudine, nevirapine, patient compliance, saliva, zidovudine.

\section{INTRODUCTION}

Oral fluids have been introduced since the early eighties as a matrix for detection and quantification of drugs and drugs of abuse. Compared to blood sampling, whole saliva has several important advantages: fluid collection is noninvasive, skin irritation or bruising in patients with poor venous access can be avoided and sample collection is safe. Further, saliva is a cost-effective tool for screening a large population and allows multiple sample collections at any time of the day [1]. However, saliva cannot be used as a simple substitute for blood testing since pharmacokinetic characteristics of many drugs are more complex in saliva than in blood [2].

Few studies investigated the use of saliva for therapeutic drug monitoring (TDM) and/or compliance control studies in HIV infected patients undergoing antiretroviral therapy (HAART) [3-6]. Rolinski and collaborators have shown a good correlation between plasma and salivary concentrations of zidovudine (ZDV) in ten HIV-infected patients suggesting that stimulated saliva might be an appropriate specimen for ZDV-TDM [3]. Plasma nevirapine (NVP) concentrations were strongly correlated with stimulated saliva levels from

*Address correspondence to this author at the Laboratory of Retrovirology, CRP-Santé, Rue Val Fleuri, 84, L-1526 Luxembourg; Tel: 00352 26970 319; Fax: 0035226970 221; E-mail: alain.gras@crp-sante.lu

${ }^{\S}$ Data previously presented in part at the $10^{\text {th }}$ International Workshop on Clinical Pharmacology of HIV Therapy; $15^{\text {th }}-17^{\text {th }}$ April 2009, Amsterdam, The Netherlands (Review in Antiviral Therapy - Volume 2; 2009).
NVP-treated adults [4]. Although indinavir concentrations in saliva were shown to be related to plasma concentrations, the authors of the study did not recommend saliva for TDM because of significant intra and inter individual variations [5]. However, a correlation between two matrix values does not automatically imply a good agreement between two methods of measurement. The Bland and Altman method [7] is the method of choice to assess graphically agreement between two body fluids. Using this method, agreement between plasma and non stimulated NVP saliva levels in children on multi-HAART regimen was reported [6].

The majority of HIV-infected individuals are living in Sub-Saharan Africa. More than 75000 individuals received HAART in Rwanda in 2009. Although virological and immunological outcomes to HAART in Rwanda were comparable to western countries [8-10], routine supervision and adherence data are limited [10]. The aim of our study was to investigate the agreement between salivary and plasma concentrations of ZDV, lamivudine (3TC) and NVP for adherence and pharmacokinetic studies in resource limited settings.

\section{MATERIAL AND METHODS}

\section{Study Group}

The study was a cross-sectional design in a prospective cohort initiated by the ESTHER ("Ensemble de Solidarité Thérapeutique Hospitalière en Réseau") project at the HIV clinic of the Treatment Research AIDS Center (TRAC) in Kigali. All participants signed a written consent form before 
being enrolled into the survey. HAART treatment consisted of ZDV/3TC (Combivir ${ }^{\circledR}$, GlaxoSmithKline, London) and NVP (Viramune ${ }^{\circledR}$, Boehringer Ingelheim, Ingelheim) taken twice daily. The total daily dose was $600 \mathrm{mg}$ ZDV, $300 \mathrm{mg}$ $3 \mathrm{TC}$ and $400 \mathrm{mg}$ NVP. Adherence to the antiretroviral (ARV) treatment was controlled by frequent questionnaires and pill counts. Patient characteristics are summarized in Table 1.

Table 1. Characteristics of the 29 HIV-1 Infected Patients

\begin{tabular}{|c|c|c|}
\hline \multicolumn{2}{|c|}{ Patient Characteristics } & Value \\
\hline Gender, $n$ & $\begin{array}{l}\text { Women } \\
\text { Men }\end{array}$ & $\begin{array}{c}23 \\
6\end{array}$ \\
\hline Age, years & $\begin{array}{c}\text { Mean (SD) } \\
\text { Range }\end{array}$ & $\begin{array}{c}40.7(8.1) \\
27-60\end{array}$ \\
\hline Body weight, kg & $\begin{array}{c}\text { Mean (SD) } \\
\text { Range }\end{array}$ & $\begin{array}{c}57.1(9.1) \\
40-75\end{array}$ \\
\hline CD4 cell count ${ }^{a}$, cells $/ \mathbf{m m}^{3}$ & $\begin{array}{c}\text { Mean (SD) } \\
\text { Range }\end{array}$ & $\begin{array}{c}195.0(122.4) \\
3-588\end{array}$ \\
\hline WHO clinical stage, $n(\%)$ & $\begin{array}{l}1 \\
2 \\
3 \\
4\end{array}$ & $\begin{array}{c}1(3) \\
4(14) \\
19(66) \\
5(17)\end{array}$ \\
\hline
\end{tabular}

\section{Sample Collection and Preparation}

Blood and saliva samples were collected during a routine consultation, 3 to 5 hours (mean $225 \mathrm{~min}$ ) after the last drug intake. Saliva was collected using a Salivette ${ }^{\circledR}$ (Sarstedt AG \& Co., Nümbrecht, Germany) containing a roll-shaped saliva collector impregnated with citric acid to stimulate salivation. The swab was chewed for one to two minutes and placed back in the insert. Plasma and salivettes were shipped on dry ice to Luxembourg and stored at $-20^{\circ} \mathrm{C}$ before analysis. Then the salivettes were centrifuged for 5 minutes at $3500 \mathrm{~g}$ to collect the saliva while the swabs were washed with an ethyl acetate/methanol mixture $(1 / 1, \mathrm{v} / \mathrm{v})$. Extracts were evaporated and the residual saliva added to the previously collected saliva. One milliliter of saliva or plasma was then mixed to $1 \mathrm{ml}$ ammonium buffer at $\mathrm{pH} 9.5$ and Mebeverine which served as internal standard. Unbound ARVs were extracted with solid phase extraction cartridges as described earlier [11, 12]. After evaporating the extracts to dryness under nitrogen at $40^{\circ} \mathrm{C}$, the residues were reconstituted in $100 \mu 1$ ammonium formate buffer $(\mathrm{pH} 3.8)$ for quantitative analysis.

\section{Antiretroviral Drug Concentration Measurements}

Detection and quantification of ARV drugs was carried out on a high performance liquid chromatography system coupled to a $\mathrm{LCQ}^{\mathrm{TM}}$ Duo Ion Trap Detector (Thermo Electron, Zellik, Belgium) equipped with an electrospray ionization interface and operated in both positive and negative ion mode. The separation of sample components was achieved on an XTerra ${ }^{\circledR}$ MS C18 column (5 $\mu$ m particle size, $3.9 \times 150 \mathrm{~mm}$, Waters, Overijse, Belgium), equipped with a similar pre-column $(10 \mathrm{~mm})$. The mobile phase consisted of a mixture of $5 \mathrm{mM}$ ammonium formate buffer at $\mathrm{pH} 3.8$ and acetonitrile. Validation parameters for the quantification method included determination of extraction yield, establish interday and intraday accuracy and repeatability as well as verification of absence of ion suppression in the calibration range. Six point calibration curves covering the therapeutic ranges of the ARV drugs were established and all $r^{2}$ were $\geq 0.98$.

\section{Statistics}

ARV concentrations were analyzed using R v.2.10.1. Applying the Bland-Altman method [13], log differences between saliva and plasma measurements were plotted against their average log concentration to determine the bias and the $95 \%$ limits of agreement (bias \pm 1.96 standard deviation, SD). The Shapiro-Wilk test was used to assess normality of log differences, one condition of the BlandAltman method. A linear regression analysis was used to confirm the lack of relationship between the two measurements and the average concentration (both expressed in $\log$ ). If saliva minus plasma levels were still related to the average concentration after $\log$ transformation, a regression approach for non-uniform differences was applied [14] and regression based limits of agreement for the difference in drug concentrations were calculated. According to the Bland and Altman's recommendation, 95\% limits of agreement for a saliva/plasma (S/P) ratio with back-transformed log values was then calculated.

\section{RESULTS}

Mean and median concentrations of unbound ZDV, 3TC and NVP in saliva and plasma of the 29 HIV-1 infected Rwandan patients are given in Table 2. Seven patients demonstrated saliva ZDV concentrations below the detection limit with two also showing undetectable plasma ZDV. Among these seven patients, five had indiscernible 3TC salivary levels. One patient was considered as an outlier for saliva ZDV concentrations because the range observed was 10 fold higher than the physiological concentrations. These saliva and plasma concentrations have not been included in the statistical analysis. NVP was detected in all plasma and saliva samples (concentrations ranging from 207 to 9730 $\mathrm{ng} / \mathrm{ml}$ in saliva and from 417 to $8917 \mathrm{ng} / \mathrm{ml}$ in plasma).

Average unbound ZDV was higher in the saliva compartment than in the plasma with a mean $\mathrm{S} / \mathrm{P}$ ratio of 4.0 \pm 9.8 (mean \pm SD) whereas unbound 3TC plasma concentrations were higher than salivary concentrations in all patients (mean $\mathrm{S} / \mathrm{P}$ ratio $=0.3 \pm 0.2$, Table 2). Mean concentrations of unbound NVP were similar in plasma and in saliva with a mean $\mathrm{S} / \mathrm{P}$ ratio of $1.5 \pm 2.1$. For NVP, 15/29 patients had a $\mathrm{S} / \mathrm{P}$ ratio $<1$ indicating a high heterogeneity of the blood-saliva diffusion between individuals. Interestingly, most patients $(10 / 15)$ with a ratio $<1$ for NVP had also a ratio $<1$ for $\mathrm{ZDV}$.

A relationship between the differences of plasma and saliva drug concentrations and the average concentrations in the two measurements was established for each drug 
Table 2. Mean and Median of Antiretroviral Drug Concentrations in Plasma and Saliva

\begin{tabular}{|c|c|c|c|}
\hline $\begin{array}{l}\text { Plasma concentrations }^{\mathrm{a}} \\
\text { Mean (SD) } \\
\text { Median (IQR) }\end{array}$ & $\begin{array}{l}n=26 \\
205(179) \\
148(107-286)\end{array}$ & $\begin{array}{l}n=29 \\
1349(759) \\
1213(837-1965)\end{array}$ & $\begin{array}{l}n=29 \\
3045(2302) \\
2707(914-4586)\end{array}$ \\
\hline $\begin{array}{l}\text { Salivary concentrations } \\
\text { Mean (SD) } \\
\text { Median (IQR) }\end{array}$ & $\begin{array}{l}n=21 \\
498(789) \\
238(84-612)\end{array}$ & $\begin{array}{l}n=24 \\
372(438) \\
197(161-350)\end{array}$ & $\begin{array}{l}n=29 \\
2769(2513) \\
1558(462-4547)\end{array}$ \\
\hline $\begin{array}{l}\text { Saliva/Plasma ratio } \\
\text { Mean (SD) }\end{array}$ & $\begin{array}{l}n=21 \\
4.0(9.8)\end{array}$ & $\begin{array}{l}n=24 \\
0.3(0.2)\end{array}$ & $\begin{array}{l}n=29 \\
1.5(2.1)\end{array}$ \\
\hline
\end{tabular}

${ }_{\mathrm{a}}^{\mathrm{a}}$ Unbound plasma concentrations in $\mathrm{ng} / \mathrm{ml} ;{ }^{b}$ Unbound saliva concentrations in $\mathrm{ng} / \mathrm{ml}$; IQR, interquartile range; $\mathrm{n}$, number of patients; SD, standard deviation.

$(\mathrm{p}<0.05 ;$ Table 3$)$. Therefore, each sample was finally defined by the log saliva (S) - log plasma (P) difference and the average $\log$ concentrations $[7,13,14]$. The logtransformed measurement differences followed the normal distribution for each drug. The ZDV plot revealed a linear relationship between the log difference and average log concentration whereas the log difference of 3TC and NVP were consistent across the range of average log concentrations (Fig. 1). The log-based linear regression model confirmed the independence of the $\log (\mathrm{S})-\log (\mathrm{P})$ differences and log average for both 3TC and NVP (Table 3). The plots revealed a good agreement between salivary and plasma concentrations with only one sample outside the limits of agreement for NVP (Fig. 1). However, the estimated limits of agreement between the two matrices were relatively high for both $3 \mathrm{TC}$ and NVP (within 0.03 and 1.13 for the 3TC S/P ratio and 0.06 and 9.09 for the NVP S/P ratio). Using linear regression analyses, we could confirm a significant relationship between the $\log (\mathrm{S})-\log (\mathrm{P})$ differences and the average ZDV log concentration $(\mathrm{p}<0.05$, Table 3). Therefore, regression based limits of agreement for non-uniform differences in ZDV concentrations were calculated as previously described [14]. As shown in Fig. (2), the differences in ZDV saliva and plasma concentrations increased with increasing drug concentrations. The statistical relation between the ZDV difference saliva - plasma (y) and the mean concentrations (x) was expressed as follows: $\mathrm{y}=$ $380.15+1.79$ x. A good agreement between the two values was observed; only one ZDV sample was outside the limits of agreement but large 95\% limits of agreement were obtained $(-1104.84+1.79 x, 344.54+1.79 x)$.

\section{DISCUSSION}

A number of clinical trials have demonstrated that plasma concentrations of antiretroviral drugs are an important factor for treatment response [15]. Concentration based antiretroviral drug dose reduction might increase access to safer therapy while preserving viral load suppression [16, 17]. In contrast, inadequate drug concentrations, often due to drug adherence failure, may lead to appearance of toxicity or drug resistance mutations. Lack of compliance of HAART-treated patients is estimated to occur between $40 \%$ and $60 \%$ of patients [18]. Combined with resistance tests, assessment of adherence may prove to be useful in developing countries [19] to preserve limited second line treatment. Genotypic resistance testing has been initiated in Rwanda [8, 9, 20] and close monitoring of patients at risk has been proposed as a relevant strategy [21]. To our knowledge, our study is the first study evaluating the utility of saliva in a Sub-Saharan population for which specific genetic background, medications and diet might influence differently antiretroviral pharmacokinetics both in plasma and saliva.

Although we showed a good agreement between saliva and plasma levels of ZDV, 3TC and NVP, the high inter individual variability represented by large $95 \%$ limits of agreement does not allow an accurate quantitative deduction of plasma ARV levels based on saliva ARV concentrations. In plasma, the inter patient variability of antiretroviral drugs has been reported by us $[11,12]$ and by others $[22,23]$ and has been attributed to genetic influences, diet and/or presence of other drugs and diseases [24-26]. In saliva, the parameters responsible for drug concentration variations may be salivary flow rate, salivary $\mathrm{pH}$, and drug pharmacokinetics. The salivary flow rate varies as a function of nutritional and emotional state, age, presence of diseases and/or presence of other drugs [27]. High inter individual but low intra individual variation of saliva $\mathrm{pH}$ has been described [28]. Variations in $\mathrm{S} / \mathrm{P}$ ratios between individuals may also be linked to differences in bound and unbound drug concentrations in plasma. This variation was reported to be high for NVP [29], relatively low for ZDV [30] and to vary as a function of age for 3TC [31].

Predicting plasma ARV concentrations from saliva is based on the assumption that saliva drug concentrations are related to unbound blood levels of the drug. The blood saliva transfer of drugs appears to be a passive diffusion process. The $\mathrm{S} / \mathrm{P}$ ratio has been described as a function of drug $\mathrm{pKa}$, of differences in drug protein binding in blood and saliva and the $\mathrm{pH}$ in the saliva and plasma [32]. In normal physiological conditions (blood $\mathrm{pH}$ of 7.4 and a saliva $\mathrm{pH}$ range from 5.5 - 7.9), considering a $\mathrm{pKa}$ of 9.7 and an unbound drug fraction of 0.81 for $\mathrm{ZDV}, 4.3$ and 0.64 for $3 \mathrm{TC}$ and 2.8 and 32 for NVP respectively, the $\mathrm{S} / \mathrm{P}$ ratios for the three drugs were estimated to vary from 0.3 to 64 for ZDV, 0.1 to 2.0 for $3 \mathrm{TC}$ and 0.1 to 1.0 for NVP depending on the saliva $\mathrm{pH}$. In our study, the average $\mathrm{S} / \mathrm{P}$ values of unbound ZDV, 3TC and NVP were 4.0, 0.3 and 1.5 respectively. With its pKa of $9.7, \mathrm{ZDV}$ is present in plasma in a non-ionized form and has fewer difficulties to diffuse 

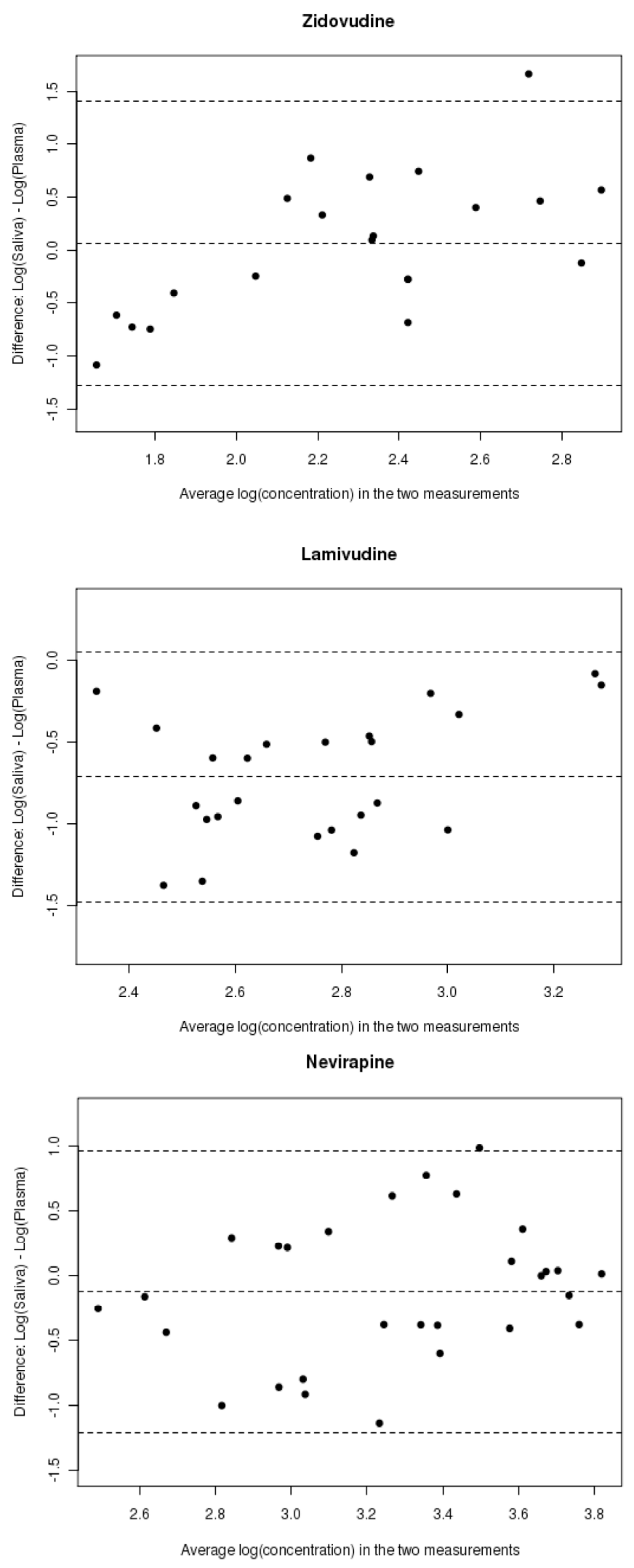

Fig. (1). Zidovudine (ZDV), lamivudine (3TC) and nevirapine (NVP) Bland-Altman plots representing the differences between log saliva and $\log$ plasma as a function of the average log concentrations. The ZDV plot showed a relationship between the $\log$ differences and the mean log concentrations. A good agreement between the two body fluids for 3TC and NVP was observed.

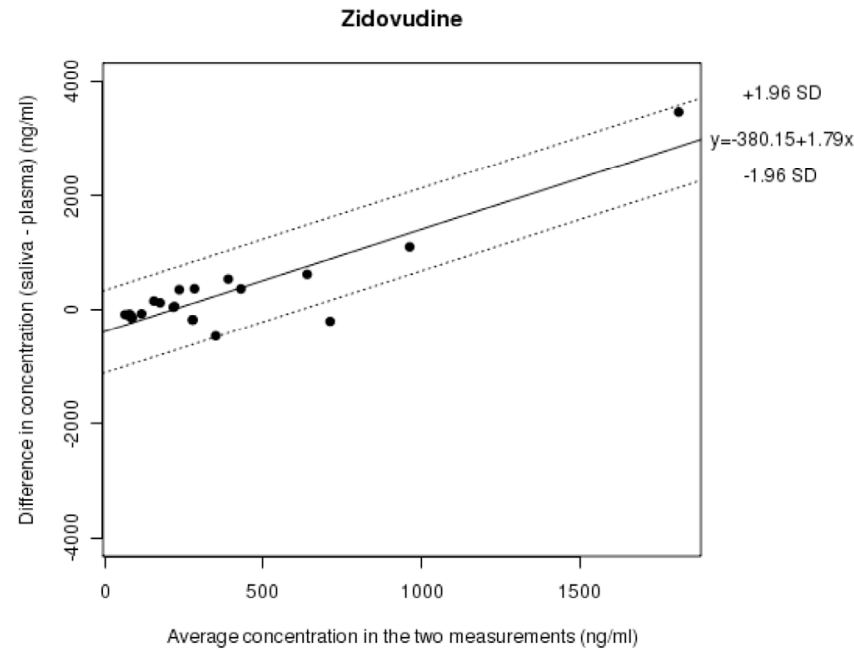

Fig. (2). Linear regression plot between the saliva minus plasma concentration differences and the average concentrations in the two matrices following the equation $y=-380.15+1.79 x$. One sample was outside the limits of agreement.

Table 3. Statistical p-Values of the Linear Regression Analysis for Zidovudine, Lamivudine and Nevirapine Bland-Altman Plots

\begin{tabular}{|l|l|l|l|}
\hline & \multicolumn{1}{|c|}{ Zidovudine } & \multicolumn{1}{|c|}{ Lamivudine } & Nevirapine \\
\hline p-value $^{\mathbf{a}}$ & $8.62 \mathrm{E}-10$ & 0.02 & 0.04 \\
\hline p-value $^{\mathbf{b}}$ & 0.00224 & 0.055 & 0.171 \\
\hline
\end{tabular}

${ }^{a}$ Relation between saliva minus plasma difference and average concentrations; ${ }^{\mathrm{b}}$ Relation between difference of $\log$ saliva and log plasma and average log concentrations.

through the cell membranes than the ionized $3 \mathrm{TC}$ (pKa of 4.3). Thus, unbound 3TC concentrations were found to be higher in plasma than in saliva. Independent of the presence of ionized NVP molecules at $\mathrm{pH} 7.4$, the mean unbound salivary concentration of NVP was as high as the plasma levels that might be a consequence of its greater lipophilicity as compared to ZDV and 3TC.

Based on correlation coefficients, ZDV and NVP concentrations were previously significantly related in the two matrices $[3,4,6]$. We also observed a significant correlation by the non parametric Spearman correlation rank test for each ARV (data not shown). However, the use of correlation coefficients to compare two different biological compartments is misleading $[7,13,14]$ as the physiological parameters modulating the drug concentrations in the two body fluids are diverse. Using the Bland-Altman analysis, the 3TC and NVP plots indicated a non equal distribution in the two matrices among the patients, while the ZDV plot revealed a linear relationship between the log difference in saliva and plasma concentrations and the mean log concentrations. Although an accurate prediction of ZDV plasma concentrations can be deduced from a linear equation, the large $95 \%$ limits of agreement as well as the 7 samples without detectable saliva concentrations have to be taken into account and may hint towards other influent parameters in these patients. 
TDM is recommended to decipher drug interactions or to explain poor response to treatment and side-effects related to high dose of antiretroviral drugs in HIV-infected patients. Considering that we did not address the question of TDM in our study that only included a limited number of patients, the usability of saliva seems ambiguous. In conclusion, our data suggest that saliva may only be used for NVP as a valuable tool for compliance testing in resource limited countries.

\section{ACKNOWLEDGEMENTS}

The authors are greatly indebted to the Rwandan patients for taking part in the study and to the health-care workers for collecting the samples. The authors also acknowledge LuxDevelopment, the "Fonds National de la Recherche" (FNR) of Luxembourg for its financial support [TR-PHD BFR08/072] as well as the "Fonds de lutte contre le trafic de stupéfiants" for the LC/MS-MS. No potential conflict of interest exists.

The design of this research study was carried out by Vic Arendt and Jean-Claude Schmit. Christine Omes and JeanClaude Karasi selected the patients, collected the clinical data and submitted the project to the Rwandese Ethical Committee. The blood sample collection was supervised by Anne-Pascale Henry. Serge Schneider and Alain Gras developed the ARV quantification method and carried out the concentration measurements. Anne-Marie Ternes and Nicolas Sauvageot performed the statistical analysis. Carole Seguin-Devaux and Serge Schneider analysed the data and were involved in the writing of the manuscript. All authors have read and approved the final version of the manuscript.

\section{REFERENCES}

[1] Choo RE, Huestis MA. Oral fluid as a diagnostic tool. Clin Chem Lab Med 2004; 42(11): 1273-87.

[2] Drummer OH. Drug testing in oral fluid. The Clin biochemist 2006; 27(3): 147-59.

[3] Rolinski B, Wintergerst U, Matuschke A, et al. Evaluation of saliva as a specimen for monitoring zidovudine therapy in HIV-infected patients. AIDS 1991; 5(7): 885-8.

[4] van Heeswijk RP, Veldkamp AI, Mulder JW, et al. Saliva as an alternative body fluid for therapeutic drug monitoring of the nonnucleoside reverse transcription inhibitor nevirapine. Ther Drug Monit 2001; 23(3): 255-8.

[5] Hugen PW, Burger DM, de Graaff M, et al. Saliva as a specimen for monitoring compliance but not for predicting plasma concentrations in patients with HIV treated with indinavir. Ther Drug Monit 2000; 22(4): 437-45.

[6] Rakhmanina NY, Capparelli EV, van den Anker JN, et al. Nevirapine concentration in nonstimulated saliva: an alternative to plasma sampling in children with human immunodeficiency virus infection. Ther Drug Monit 2007; 29(1): 110-7.

[7] Bland JM, Altman DG. Statistical methods for assessing agreement between two methods of clinical measurement. Lancet. 1986 8; 1(8476): 307-10.

[8] Fischer A, Karasi JC, Kibibi D, et al. Antiviral efficacy and resistance in patients on antiretroviral therapy in Kigali, Rwanda: the real-life situation in 2002. HIV Med 2006; 7(1): 64-6.

[9] Karasi JC, Servais JY, Musonera F, et al. Immunovirological outcomes and drug resistance profiles of the Rwandese HIV ART Cohort. 7th European HIV Drug Resistance Workshop 25-27 March, 2009 Stockholm, Sweden Reviews in Antiviral Therapy. p. Abstract \#24.

[10] Lowrance DW, Ndamage F, Kayirangwa E, et al. Adult clinical and immunologic outcomes of the national antiretroviral treatment program in Rwanda during 2004-2005. J Acquir Immune Defic Syndr. 2009 1; 52(1): 49-55.

[11] Schneider S, Peltier A, Gras A, et al. Efavirenz in human breast milk, mothers', and newborns' plasma. J Acquir Immune Defic Syndr 2008; 48(4): 450-4.

[12] Lemmer P, Schneider S, Schuman M, et al. Determination of nevirapine and efavirenz in plasma using GC/MS in selected ion monitoring mode. Ther Drug Monit. 2005; 27(4): 521-5.

[13] Bland JM, Altman DG. Comparing methods of measurement: why plotting difference against standard method is misleading. Lancet 1995 21;346(8982): 1085-7.

[14] Bland JM, Altman DG. Measuring agreement in method comparison studies. Stat Methods Med Res. 1999; 8(2): 135-60.

[15] Rakhmanina NY, van den Anker JN, Soldin SJ. Therapeutic drug monitoring of antiretroviral therapy. Aids Patient Care STDS 2004; 18(1): 7-14.

[16] Gatanaga H, Hayashida T, Tsuchiya K, et al. Successful efavirenz dose reduction in HIV type 1-infected individuals with cytochrome P450 2B6*6 and *26. Clin Infect Dis 2007; 45(9): 1230-7.

[17] Rendon A, Nunez M, Jimenez-Nacher I, Gonzalez de Requena D, Gonzalez-Lahoz J, Soriano V. Clinical benefit of interventions driven by therapeutic drug monitoring. HIV Med 2005; 6(5): 360-5.

[18] Simoni JM, Frick PA, Lockhart D, Liebovitz D. Mediators of social support and antiretroviral adherence among an indigent population in New York City. Aids Patient Care STDS 2002; 16(9): 431-9.

[19] Fraaij PL, Rakhmanina N, Burger DM, de Groot R. Therapeutic drug monitoring in children with HIV/AIDS. Ther Drug Monit. 2004; 26(2): $122-6$.

[20] Karasi JC, Musonera F, Servais JY, et al. HIV-1 molecular epidemiology and prevalence of drug resistance in treatment -naïve and HAART-treated patients between 2003 and 2009 in Rwanda. International HIV and Hepatitis Virus Drug Resistance Workshop and Curative Strategies 8-12 June, 2010 Dubrovnik, Croatia Antiretroviral Therapy. p. A143.

[21] van Griensven J, Zachariah R, Rasschaert F, Mugabo J, Atte EF, Reid T. Stavudine- and nevirapine-related drug toxicity while on generic fixed-dose antiretroviral treatment: incidence, timing and risk factors in a three-year cohort in Kigali, Rwanda. Trans R Soc Trop Med Hyg 2010; 104(2): 148-53.

[22] Fabbiani M, Di Giambenedetto S, Bracciale L, et al. Pharmacokinetic variability of antiretroviral drugs and correlation with virological outcome: 2 years of experience in routine clinical practice. J Antimicrob Chemother 2009; 64(1): 109-17.

[23] Clevenbergh P, Mouly S, Sellier P, et al. Improving HIV infection management using antiretroviral plasma drug levels monitoring: a clinician's point of view. Curr HIV Res 2004; 2(4): 309-21.

[24] de Maat MM, Huitema AD, Mulder JW, Meenhorst PL, van Gorp EC, Beijnen JH. Population pharmacokinetics of nevirapine in an unselected cohort of HIV-1-infected individuals. Br J Clin Pharmacol 2002; 54(4): 378-85.

[25] Macnab KA, Gill MJ, Sutherland LR, De Boer Visser N, Church D. Erratic zidovudine bioavailability in HIV seropositive patients. J Antimicrob Chemother. 1993; 31(3): 421-8.

[26] Ivanovic J, Nicastri E, Ascenzi P, et al. Therapeutic drug monitoring in the management of HIV-infected patients. Curr Med Chem 2008; 15(19): 1925-39.

[27] Shannon IL, Suddick RP, Dowd FJ, Jr. Saliva: composition and secretion. Monogr Oral Sci 1974; 2: 1-103.

[28] Grossman L, Brickman B. Some Observations on the $\mathrm{pH}$ of Saliva. J Dent Res 1937; 16: 409-16.

[29] Almond LM, Boffito M, Hoggard PG, et al. Nevirapine Protein Binding in HIV Infected Individuals. 6th International Congress on Drug Therapy in HIV Infection 17-21 November 2002 Glasgow, UK Int Cong Drug Therapy HIV 2002 Nov 17-21. p. Abstract No. P164.

[30] Rolinski B, Wintergerst U, Goebel FD, Roscher AA, Belohradsky BH. Determination of the protein-bound fraction of zidovudine in serum. 7th International AIDS Conference June 16-21, 1991 Florence, Italy. p. 208. Abstract\#W.B.2107.

[31] Johnson MA, Moore KH, Yuen GJ, Bye A, Pakes GE. Clinical pharmacokinetics of lamivudine. Clin Pharmacokinet 1999; 36(1): 4166.

[32] Rasmussen F. Salivary Excretion of Sulphonamides and Barbiturates by Cows and Goats. Acta Pharmacol Toxicol (Copenh) 1964; 21: 11-9. 